\title{
Length of hospital stay after delivery among Danish women with congenital heart disease: a register-based cohort study
}

\author{
Anne Marie Kirkegaard ${ }^{1 \dagger}$, Maria Breckling ${ }^{1 \dagger}$, Dorte Guldbrand Nielsen²,3, Janne S. Tolstrup ${ }^{1}$, \\ Søren Paaske Johnsen ${ }^{4}$, Annette Kjær Ersbøll ${ }^{1}$ and Stine Kloster ${ }^{1^{*}}$
}

\begin{abstract}
Background: The literature about the impact of congenital heart disease (CHD) on the length of hospital stay after delivery is limited, and nonexisting in a country with free and equal access to healthcare. We aimed to examine the hypothesis that Danish women with CHD have a longer hospital stay after delivery compared to women without CHD. Secondarily, we aimed to examine the hypothesis that cesarean section modifies the association.

Methods: The study was a national cohort study using Danish nationwide registers in 1997-2014. Maternal CHD was categorized as simple, moderate, or complex CHD. The comparison group consisted of women without CHD. Outcome of interest was length of hospital stay after delivery registered in complete days. Mode of delivery was categorized as cesarean section or vaginal delivery. Data was analyzed using a generalized linear model with a Poisson distribution.

Results: We included 939,678 births among 551,119 women. Women without CHD were on average admitted to the hospital for 3.6 (SD 3.7) days, whereas women with simple, moderate, and complex CHD were admitted for 3.9 (SD 4.4), 4.0 (SD 3.8) and 5.1 (SD 6.7) days, respectively. The adjusted length of hospital stay after delivery was $12 \%$ (relative ratio $(R R)=1.12,95 \%$ confidence interval $(C l) 1.07-1.18), 14 \%(R R=1.14,95 \% C l: 1.07-1.21)$, and $45 \%(R R=1.45,95 \%$ Cl: 1.24-1.70) longer among women with simple, moderate, and complex CHD, respectively, compared to women without CHD. The association between maternal CHD and length of hospital stay was not modified by mode of delivery ( $p$-value of interaction $=0.62$ ). Women who gave birth by cesarean section were on average admitted to the hospital for 2.7 days longer compared to women with vaginal delivery.

Conclusion: The hospital stay after delivery was significantly longer among women with CHD as compared to women without CHD. Further, higher complexity of CHD was associated with longer length of stay. Cesarean section did not modify the association.
\end{abstract}

Keywords: Congenital heart disease, Pregnancy, Length of hospital stay

*Correspondence: stkl@sdu.dk

${ }^{\dagger}$ Anne Marie Kirkegaard and Maria Breckling shared first authorship/ contributed equally.

${ }^{1}$ National Institute of Public Health, University of Southern Denmark, Studiestræde 6, 1455 Copenhagen K, Denmark

Full list of author information is available at the end of the article

\section{Background}

Globally, there has been an increase in the number of adults living with congenital heart disease (CHD) [1-3], due to improvement in both diagnosing and medical care. This results in more women with CHD reaching the childbearing age, and both the number and proportion of women with CHD giving birth is on the rise [4-7]. 
Most women with CHD will be able to complete a pregnancy, despite a larger proportion of women with CHD experiencing more cardiac, obstetric, and neonatal complications compared to women without CHD [7-11]. Several American studies have also shown an association between CHD and length of hospital stay after delivery $[6,7,12-16]$ which might reflect a more complicated delivery [12], a greater proportion of deliveries by cesarean section $[5,7,11,12,17,18]$ and more preterm births $[7-9,11,17]$ that result in hospitalization, or healthcare workers' precautions for early discharge of women with known CHD. However, in a setting with user paid healthcare the length of hospital stay might also be influenced by insurance status and socioeconomic position $[19,20]$.

The length of hospital stay after delivery among women with CHD has not been investigated in a healthcare system with free and equal access as e.g. the Danish healthcare system. This information is important for healthcare workers and healthcare authorities in order to have an unbiased estimate, when planning resources directed to the growing population of women with CHD surviving into the childbearing age. Furthermore, the knowledge can help elucidate whether the length of stay differs in a public healthcare system compared to others, as one may wonder if public financed systems are more cautious to discharge patients because the patients do not pay directly. Therefore, our primary aim was to examine the hypothesis that women with CHD have a longer hospital stay after delivery compared to women without $\mathrm{CHD}$ in a healthcare system with free and equal access. The secondary aim was to examine the hypothesis that cesarean section modifies the association between CHD and length of stay, i.e., the association between CHD and the length of hospital stay differs depending on whether the birth is a vaginal delivery or a cesarean section.

\section{Methods}

We performed a nationwide cohort study with data from the Danish Medical Birth Register [21, 22] and the Danish National Patient Register [23, 24]. In Denmark, all citizens are assigned a unique personal identification number, which enables individual-level linkage of national registers $[25,26]$.

\section{Study population}

The study population consisted of births between 1997 and 2014, registered in the Danish Medical Birth Register. The register holds information on all live and stillbirths registered in Denmark, including information of both mother and child related to the pregnancy and delivery [21, 22]. Only births of women born in Denmark were included to secure equal opportunity for CHD diagnosing among women. We included all singleton births $(n=952,882)$.

\section{Maternal congenital heart disease}

Information about maternal CHD was obtained from the Danish National Patient Register, which is a populationbased administrative register holding information on all hospital admissions since 1977 and all outpatients contacts since 1995 [23, 24]. All women with a diagnosis of CHD (International Classification of Diseases and Health Related problems, Tenth Revision (ICD-10): Q20-Q26, International Classification of Diseases, Eighth Revision (ICD-8): 746-747) between 1977 and 2015 were included except ICD-10: Q26.5-Q26.6 and ICD-8: 746.7 and 747.5-747.9, which are not specific for CHDs. Additionally, we excluded invalid diagnoses of CHD or inaccurate coding in the Danish National Patient Register; for example by excluding diagnoses of patent ductus arteriosus if diagnosed before the age of 2 months without an associated operation code or by excluding diagnoses of congenital stenosis of aortic valve if diagnosed at ages $>40$ years, as has been done in previous publications [27]. Based on available diagnoses women were categorized as having no $\mathrm{CHD}$, simple, moderate or complex $\mathrm{CHD}$ as described elsewhere [8].

\section{Length of hospital stay}

Outcome of interest was length of hospital stay after delivery. Information was obtained from the Danish Medical Birth Register where length of hospital stay was reported based on date of admission and discharge in the Danish National Patient Register and reported in complete days such that the shortest possible length of stay was 1 day [21,22] . To minimize the influence of outliers and unreliable registrations of days we truncated length of hospital stay at 50 days.

\section{Covariates}

Maternal ethnicity, age, parity, educational level, and year of delivery were identified as confounders a priori using a Directed Acyclic Graph (DAG) (Supplementary Fig. S1) [28]. The DAG was created using the free software package DAGitty [29].

Information about ethnicity was obtained from the Danish Civil Registration System [26] and grouped into emigrants or descendants with Western and Non-Western origin. Information about maternal age, year of delivery, and parity was obtained from the Danish Medical Birth Register [21, 22]. Age was categorized into four categories: $<25,25-29,30-34$, and $\geq 35$ years. Year of delivery was grouped into year-bands of 5 years, except the last interval which contained 3 years. Information about parity was grouped into nulli-, primi-, and multiparous; 
corresponding to never given birth before the present pregnancy, given birth once before and more than once before. In case a woman was noted as e.g. nulliparous and was registered with more than one birth during the study period, parity was corrected based on the available number of births in the study period as described elsewhere [8].

Information on mode of delivery was obtained from the Danish Medical Birth register and categorized as having a vaginal delivery or a caesarean section.

Information about the highest level of completed education registered the 1st of October the year preceding each birth was obtained by linkage to the Danish Education Register [30]. Level of education was classified according to the International Standard Classification of Education System (ISCED) [31] and categorized into three groups; low (pre-primary, primary and lower secondary; ISCED level 1-2), medium (upper secondary and postsecondary; ISCED level 3-4), and high education (tertiary education; ISCED level 5-8).

\section{Statistical analyses}

Descriptive analysis of the study population was performed by means or frequencies (number and proportion) of births by maternal CHD. Furthermore, the timewise development in median number of days of admission after delivery were illustrated for nulli- and multiparous women according to their CHD status.

The association between maternal CHD and length of hospital stay after delivery was examined using a generalized linear model with a Poisson distribution. Women without CHD constituted the reference group. The relative ratio (RR) and 95\% confidence interval (CI) of length of hospital stay after delivery was estimated for simple, moderate, and complex CHD, respectively, as compared to length of hospital stay after delivery among women with no CHD. An unadjusted model and an adjusted model were used. Confounders included in the adjusted model were maternal age, parity, ethnicity, educational level, and year of delivery. The overall $p$-value of the effect of maternal CHD was calculated using a likelihood ratio test in the unadjusted and adjusted models. Some women had more than one birth during the study period in 1997-2014. To account for the hierarchical data structure with births nested within women, a cluster-robust standard error estimator was used.

To examine if cesarean section modified the association between maternal CHD and length of hospital stay after delivery the interaction between maternal CHD and mode of delivery was included as well as the main effect of the two variables. Wald's test was used to test the significance of the interaction term.

\section{Sensitivity analysis}

Four sensitivity analyses were performed. In the main analysis, the length of hospital stay was truncated at 50 days to minimize the influence of outliers. In the first two sensitivity analyses, the truncation of length of hospital stay was modified to 30 and 100 days, respectively. In the third sensitivity analysis, we excluded all women with a hospital stay above 50 days. In the fourth sensitivity analysis, we used a multilevel model (i.e., a generalized linear mixed model) with two levels (women and births nested within women).

\section{Ethics}

In Denmark, no ethical approval or written informed consent are required for register-based studies [32, 33].

\section{Results}

\section{Participants}

The population consisted of 952,882 births after exclusion of births with multiple pregnancies or missing information on maternal ethnicity. Furthermore, births completed before week 22 and after week 44 of completed gestation were excluded $(n=218)$. Also, implausible birthweights $(n=577)$ and missing information on length of hospital stay $(n=12,409)$ were excluded. Therefore, the final population consisted of 939,678 births among 551,119 women. The selection of the study population is illustrated in Fig. 1.

Baseline characteristics by CHD status are shown in Table 1. Overall, $15.7-20.0 \%$ of women with CHD were $<25$ years of age at birth, $45.1-48.6 \%$ were nulliparous and $22.6-27.5 \%$ had a low education compared to $12.6,43.9$ and $19.1 \%$ of women without CHD, respectively. Additionally, a greater proportion of women with CHD had a cesarean section as compared to women without CHD (29.2\% (for women with complex CHD) versus $18.5 \%)$.

\section{Length of hospital stay}

The length of hospital stay after delivery was significantly longer among women with CHD than among women without CHD. Further, the length of stay was longer among women with higher severity of the CHD with average hospital stays of 3.6 (SD 3.7), 3.9 (SD 4.4), 4.0 (SD 3.8) and 5.1 (SD 6.7) days for women without CHD, simple, moderate and complex CHD, respectively (Table 2). During the study period the median number of days of admission has declined regardless of CHD status and parity with nulliparous women with complex CHD having the longest stay. The decline was similar between women without CHD and complex CHD (Fig. 2). 


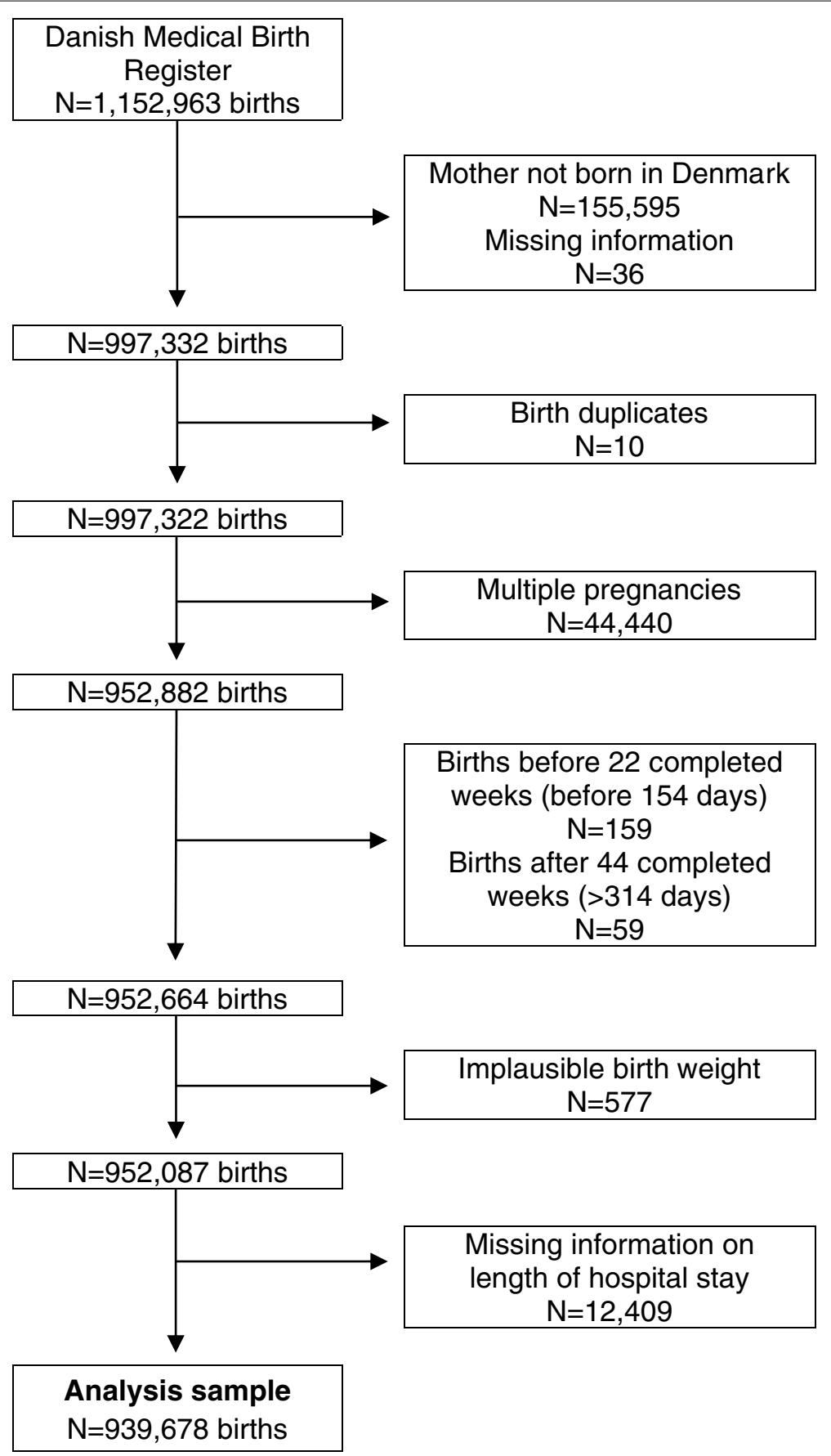

Fig. 1 Flow diagram of data from the Danish Medical Birth Register

The length of hospital stay after delivery was extended with $45 \%$ (adjusted RR $=1.45$, 95\% CI: $1.24-1.70$ ), $14 \%$ $(\mathrm{RR}=1.14,95 \% \mathrm{CI}: 1.07-1.21)$ and $12 \%(\mathrm{RR}=1.12,95 \%$ CI: 1.07-1.18) for women with complex, moderate, and simple CHD, respectively, compared to women without CHD (Table 2). There was no difference in length of hospital stay among women with moderate and simple
CHD $(p=0.70)$. The association between maternal CHD and length of hospital stay was similar in strata of mode of delivery ( $p$-value of interaction $=0.62$, Fig. 3 ). Women who had a cesarean section had on average 2.7 days longer hospital stay after delivery compared to women who did not give birth by cesarean section (Fig. 3). 
Table 1 Baseline characteristics by congenital disease status of 939,678 births in 551,119 women. Denmark, 1997-2014

\begin{tabular}{|c|c|c|c|c|c|c|c|c|}
\hline & \multicolumn{8}{|c|}{ Maternal congenital heart disease } \\
\hline & \multicolumn{2}{|l|}{ No } & \multicolumn{2}{|c|}{ Simple } & \multicolumn{2}{|c|}{ Moderate } & \multicolumn{2}{|c|}{ Complex } \\
\hline & $\mathrm{n}^{\mathrm{a}}$ & $(\%)$ & $\mathrm{n}^{\mathrm{a}}$ & $\overline{(\%)}$ & $\mathrm{n}^{\mathrm{a}}$ & $(\%)$ & $\mathrm{n}^{\mathrm{a}}$ & (\%) \\
\hline Maternal age (years) & 935,959 & & 2242 & & 1093 & & 384 & \\
\hline$<25$ & & 12.6 & & 20.0 & & 15.7 & & 19.3 \\
\hline $25-29$ & & 33.8 & & 32.9 & & 36.2 & & 35.1 \\
\hline $30-34$ & & 36.1 & & 33.4 & & 34.1 & & 34.1 \\
\hline$\geq 35$ & & 17.5 & & 13.7 & & 14.0 & & 11.5 \\
\hline Parity & 922,147 & & 2210 & & 1075 & & 381 & \\
\hline Nulli & & 43.9 & & 48.5 & & 48.6 & & 45.1 \\
\hline Primi & & 38.7 & & 36.3 & & 36.8 & & 35.2 \\
\hline Multi & & 17.4 & & 15.2 & & 14.6 & & 19.7 \\
\hline Maternal ethnicity & 935,959 & & 2242 & & 1093 & & 384 & \\
\hline Western & & 98.7 & & 97.8 & & 98.9 & & 96.4 \\
\hline Non-western & & 1.3 & & 2.2 & & 1.1 & & 3.6 \\
\hline Maternal educational level & 923,832 & & 2210 & & 1078 & & 375 & \\
\hline Low & & 19.1 & & 27.1 & & 22.6 & & 27.5 \\
\hline Medium & & 43.8 & & 40.5 & & 41.6 & & 46.4 \\
\hline High & & 37.1 & & 32.4 & & 35.8 & & 26.1 \\
\hline Year of delivery (groups) & 935,959 & & 2242 & & 1093 & & 384 & \\
\hline $1997-2001$ & & 29.6 & & 22.3 & & 25.3 & & 23.2 \\
\hline $2002-2006$ & & 28.5 & & 25.3 & & 26.3 & & 27.9 \\
\hline $2007-2011$ & & 27.5 & & 32.3 & & 30.9 & & 33.8 \\
\hline 2012-2014 & & 14.4 & & 20.1 & & 17.5 & & 16.1 \\
\hline Mode of delivery & 935,959 & & 2242 & & 1093 & & 384 & \\
\hline Cesarean section & & 18.5 & & 24.3 & & 23.1 & & 29.2 \\
\hline
\end{tabular}

${ }^{\mathrm{a}}$ Number of births

Table 2 Association between congenital heart disease and length of hospital stay after delivery given by relative ratio (RR) and 95\% confidence interval (95\% Cl). Denmark, 1997-2014

\begin{tabular}{|c|c|c|c|c|c|c|c|c|c|}
\hline & \multirow[b]{2}{*}{$n^{a}$} & \multicolumn{2}{|c|}{$\begin{array}{l}\text { Number of days of admission } \\
\text { after delivery }\end{array}$} & \multicolumn{3}{|c|}{ Unadjusted } & \multicolumn{3}{|c|}{ Adjusted $^{b}$} \\
\hline & & Mean (SD) & Median (IQR) & $\mathrm{RR}$ & $95 \% \mathrm{Cl}$ & $p$-value & RR & $95 \% \mathrm{Cl}$ & $p$-value \\
\hline $\begin{array}{l}\text { Maternal congenital } \\
\text { heart disease }\end{array}$ & & & & & & $<0.001$ & & & $<0.001$ \\
\hline No & 935,959 & $3.6(3.7)$ & $3(1-4)$ & 1 (ref) & - & & 1 (ref) & - & \\
\hline Simple & 2242 & $3.9(4.4)$ & $3(2-5)$ & 1.10 & $1.05-1.16$ & & 1.12 & $1.07-1.18$ & \\
\hline Moderate & 1093 & $4.0(3.8)$ & $3(2-5)$ & 1.13 & $1.06-1.20$ & & 1.14 & $1.07-1.21$ & \\
\hline Complex & 384 & $5.1(6.7)$ & $4(2-5)$ & 1.42 & $1.22-1.66$ & & 1.45 & $1.24-1.70$ & \\
\hline
\end{tabular}

${ }^{a}$ Number of births in the unadjusted analysis

${ }^{\mathrm{b}}$ Adjusted for maternal age, year of delivery, parity, ethnicity, and maternal educational level

\section{Sensitivity analyses}

The sensitivity analyses with length of hospital stay truncated at 30 days (Supplementary Table S1) and 100 days (Supplementary Table S2) after delivery gave almost the same results as the main analysis (truncated at 50 days; Table 2). Also, exclusion of women with hospital stays above 50 days gave similar results (Supplementary Table S3).

Additionally, modeling the association using a multilevel analysis did not change the results compared to the main analysis (Supplementary Table S4). 

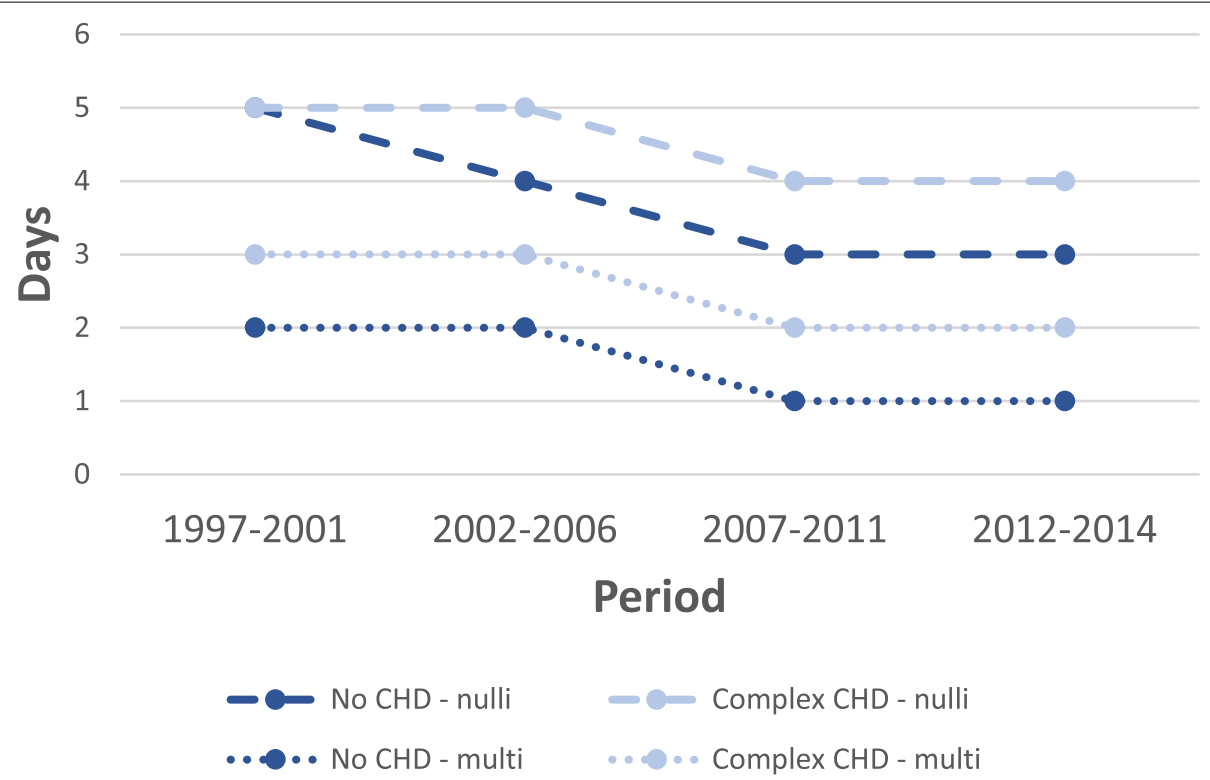

Fig. 2 Median number of days of admission after delivery among women with complex CHD and without CHD for nulliparous women and multiparous women

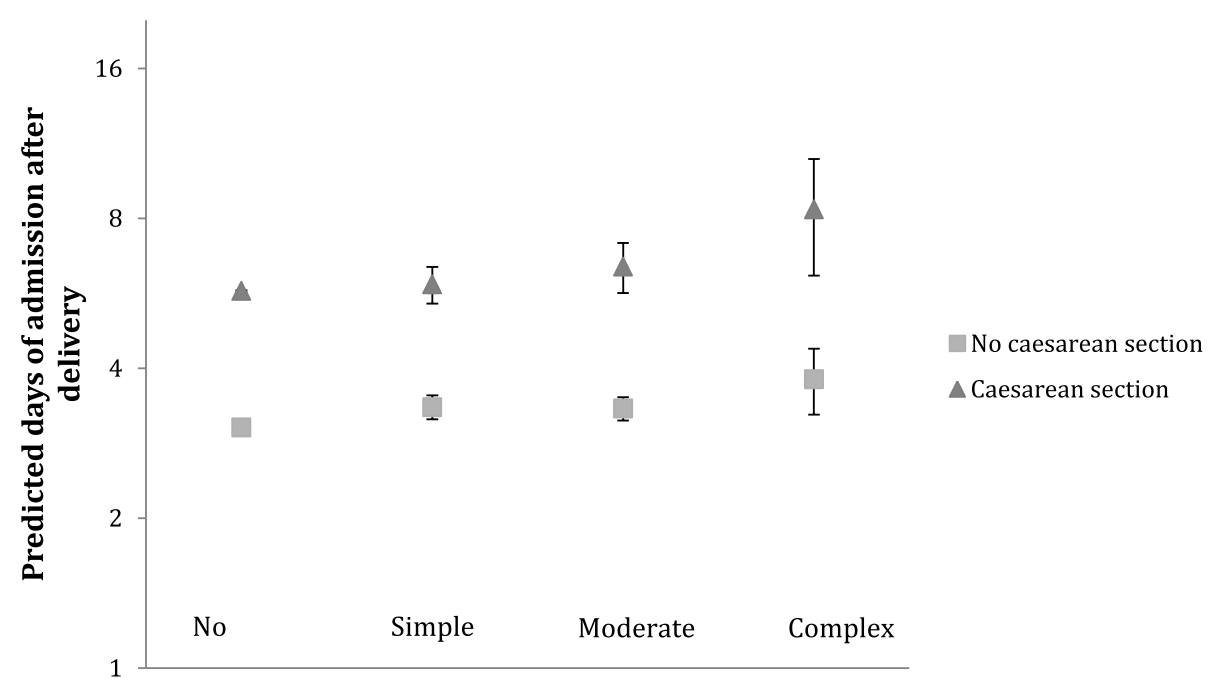

\section{Maternal congenital heart disease}

Fig. 3 Predicted days of admission after delivery by maternal congenital heart disease status and caesarean section. P-value for interaction is 0.62. Adjusted for maternal age, parity, ethnicity, educational level and year of delivery

\section{Discussion}

This nationwide register-based cohort study found that the length of hospital stay after delivery was significantly longer among women with CHD as compared to women without CHD. The hospital stay was $45 \%$ longer among women with complex CHD, 14 and $12 \%$ longer among women with moderate and simple CHD compared with women without CHD. Cesarean section did not modify the association between maternal CHD and length of hospital stay after delivery.

Our findings are supported by similar American studies, where length of maternal hospitalization on average was longer among women with CHD compared to women without $\mathrm{CHD}[6,7,12-15]$. One study reported that $23.8 \%$ of women with CHD stayed $>3$ days after delivery as compared to $13.4 \%$ of women without CHD 
[6]. Likewise, Warrick et al. [15] reported that almost half of all deliveries complicated by maternal CHD resulted in a prolonged hospital stay after both vaginal delivery and cesarean section. Additionally, Hayward et al. [14] found that $11.1 \%$ of women with complex CHD and $6.0 \%$ of women with non-complex CHD had a hospital stay more than 7 days after delivery as compared to $1.3 \%$ among women without CHD. Furthermore, a recent American study reported a mean hospital length of 2.3 days among women with CHD as compared to 1.8 days among women without CHD [12]. Also, they reported a longer hospital stay among women with more complex CHD as compared to women with simple CHD; 2.6 days versus 2.2 days. These are shorter stays compared to the length of stay in the current study. However, free and universal healthcare, as well as national guidelines most likely affect the current practice and length of hospital stay. Nevertheless, despite differences in the absolute length of stay, the pattern between women with and without CHD was similar to previous studies.

A longer admission after delivery among women with $\mathrm{CHD}$ can be a consequence of several factors that are more common among women with CHD than among women without $\mathrm{CHD}$, e.g. a higher proportion of preterm birth $[8,9,11,14,17]$, obstetric complications or cardiac complications during pregnancy and delivery $[7,10,17$, $34,35]$. It could involve a pathway from $\mathrm{CHD}$ to obstetric complications during pregnancy and delivery leading to a higher frequency of cesarean section and longer hospital stay. In line with the exiting literature, we found a higher proportion of women with CHD having cesarean section as compared to women without CHD [5, 7, 11, 12, 14, 15, $17,18,36]$. Further, we found that the length of hospitalization was longer after a cesarean section among both women with and without CHD. However, in the present study we show that the length of hospital stay is not prolonged additionally after a cesarean section among women with CHD as compared to women without CHD. This finding indicates that cesarean sections do not affect women with CHD more severely than women without CHD; at least not to an extent that is reflected in longer hospitalization. However, a longer hospital stay could also be due to caution among clinical staff. This need to be addressed in future research in order to understand if longer stay was a positive or negative outcome and further if it should or could be prevented.

There is an international trend to shorten the postpartum hospital stay among healthy women [37]. However, both early discharge and longer hospital stay among healthy women has been speculated to be associated with adverse outcomes as e.g. postpartum depression, readmission and neonatal mortality rate $[37,38]$. Among women with CHD other factors might need consideration, e.g., Hayward et al. [14] showed that women with CHD more often were readmitted to the hospital within 30 days, 1 year and 7 years after deliveryrelated discharge as compared to women without CHD. Therefore, the association between length of hospital stay and subsequent adverse maternal and neonatal outcomes needs to be investigated among women with CHD. Analyzing the number of readmissions was beyond the scope of this study, however, it may indicate how a prolonged hospital stay among women with CHD is associated with readmission rate after delivery in a Danish setting.

\section{Strengths and limitations}

The main strength of the present study was the inclusion of all women in Denmark diagnosed with CHD, minimizing the risk of selection bias compared to inclusion from specialized clinics. Further, it was possible to include women with simple CHD who often give birth in nonspecialized hospitals.

A further strength of our study is the validation of $\mathrm{CHD}$ diagnoses. A recent American study has shown that CHD diagnoses from administrative databases are associated with inaccuracy [39]. In Denmark, CHD diagnoses are in general associated with a high positive predictive value $[40,41]$. However, to increase the validity further we used an algorithm previously described (see appendix in [27]) to exclude invalid diagnoses of CHD and inaccurate coding.

Further, we find our results to be robust since similar results were found in the sensitivity analyses where the length of admission were truncated at different lengths. For a limited number of births (1039 births, $0.11 \%$ ) the hospital stay was $>50$ days and considered incorrect, most likely due to an error in the date of discharge. Therefore, number of days of admission was truncated to 50 days. However, changing the truncation to 30 days and 100 days, respectively, or excluding these observations resulted in similar results and this bias is therefore considered to be minor.

The main limitation is that the clinical data, such as blood pressure and electrocardiogram, were not accessible and, therefore, we were unable to differentiate between severity within a given CHD diagnosis when categorizing $\mathrm{CHD}$ into simple, moderate, and complex.

\section{Conclusion}

This nationwide register-based cohort study found that the hospital stay after delivery was significantly longer among women with CHD as compared to women without CHD. Further, length of stay increased with increasing CHD complexity. Cesarean section did not modify the association between maternal CHD and length of hospital stay after birth, indicating that a 
cesarean section does not affect a woman with CHD more severely than a woman without CHD; at least not to an extent that was reflected in a longer hospitalization. The results can help to highlight the need for future expenses and amount of hospital capacity in relation to prolonged hospital stays after delivery for the growing population of women with CHD. Furthermore, our results, together with the existing literature, indicate that the pattern in hospitalization is similar across private and public healthcare systems.

\section{Abbreviations \\ CHD: Congenital Heart Disease; Cl: Confidence Interval; DAG: Directed Acyclic Graph; ICD-8: International Classification of Diseases, 8th revision; ICD-10: International Classification of Diseases and Related Health Problems, 10th revision; ISCED: International Standard Classification of Education System; RR: Relative Ratio.}

\section{Supplementary Information}

The online version contains supplementary material available at https://doi. org/10.1186/s12884-021-04286-3.

Additional file 1 : Figure S1. Simplified Directed Acyclic Graph (DAG) highlighting variables of importance in the analysis of the association between maternal congenital heart disease and length of hospital stay. Table S1. Association between congenital heart disease and length of hospital stay after delivery given by relative ratio (RR) and 95\% confidence interval $(95 \% \mathrm{Cl})$. Length of hospital stay is truncated at 30 days. Table S2. Association between congenital heart disease and length of hospital stay after delivery given by relative ratio (RR) and 95\% confidence interval (95\% $\mathrm{CI}$ ). Length of hospital stay is truncated at 100 days. Table S3. Association between congenital heart disease and length of hospital stay after delivery given by relative ratio (RR) and 95\% confidence interval $(95 \% \mathrm{Cl})$. Length of hospital stay $>50$ days have been excluded. Table S4. Multilevel analysis of the association between congenital heart disease and length of hospital stay after delivery given by relative ratio (RR) and $95 \%$ confidence interval $(95 \% \mathrm{Cl})$.

\section{Acknowledgements}

Not applicable.

\section{Authors' contributions}

AMK, MB, SK and AKE participated in the conception of the study design acquisition and interpretation of the data. AMK, MB, SK and AKE had full access to the data and conducted the analyses. AMK, MB and SK drafted the first manuscript which was critically revised for important intellectual content by AMK, MB, SK, AKE, DGN, JT and SPJ. All authors have approved the submitted manuscript.

\section{Funding}

The study was funded by the Danish Heart Association (15-R99-A5849-22942). Funders had no influence on study design, analyses, manuscript preparation or publications.

\section{Availability of data and materials}

All data were provided by Statistics Denmark and due to their data privacy regulation, data with less than five individuals per cell were not reported. Data will not be made available to other researchers for the purpose of reproducing the results because this would be a violation of the Danish General Data protection Regulation [32] and data Privacy Regulation by Statistic Denmark [42].

\section{Declarations}

Ethics approval

The study was approved by the Danish Data Protection Agency (2015-57-

0008, no.16/48885). In Denmark, written informed consent or ethical approval is not required for register-based studies [32].

\section{Consent for publication}

Not applicable.

\section{Competing interests}

The authors declares that they have no competing interests.

\section{Author details}

${ }^{1}$ National Institute of Public Health, University of Southern Denmark, Studiestræde 6, 1455 Copenhagen K, Denmark. ²Department of Clinical Medicine, Aarhus University, Aarhus, Denmark. ${ }^{3}$ Department of Cardiology, Aarhus University Hospital, Aarhus, Denmark. ${ }^{4}$ Danish Center for Clinical Health Services Research, Department of Clinical Medicine, Aalborg University, Aalborg, Denmark.

Received: 31 May 2021 Accepted: 16 November 2021 Published online: 07 December 2021

\section{References}

1. Gilboa SM, Salemi JL, Nembhard WN, Fixler DE, Correa A. Mortality resulting from congenital heart disease among children and adults in the United States, 1999 to 2006. Circulation. 2010;122(22):2254-63.

2. Khairy P, lonescu-Ittu R, Mackie AS, Abrahamowicz M, Pilote L, Marelli AJ. Changing mortality in congenital heart disease. J Am Coll Cardiol. 2010;56(14):1149-57.

3. Marelli AJ, lonescu-Ittu R, Mackie AS, Guo L, Dendukuri N, Kaouache M. Lifetime prevalence of congenital heart disease in the general population from 2000 to 2010. Circulation. 2014;130(9):749-56.

4. Bottega N, Malhame I, Guo L, lonescu-Ittu R, Therrien J, Marelli A. Secular trends in pregnancy rates, delivery outcomes, and related health care utilization among women with congenital heart disease. Congenit Heart Dis. 2019;14(5):735-44.

5. Karamlou T, Diggs BS, McCrindle BW, Welke KF. A growing problem: maternal death and peripartum complications are higher in women with grown-up congenital heart disease. Ann Thorac Surg. 2011;92(6):2193-8 discussion 8-9.

6. Opotowsky AR, Siddiqi OK, D'Souza B, Webb GD, Fernandes SM, Landzberg MJ. Maternal cardiovascular events during childbirth among women with congenital heart disease. Heart. 2012;98(2):145-51.

7. Thompson JL, Kuklina EV, Bateman BT, Callaghan WM, James AH, Grotegut CA. Medical and obstetric outcomes among pregnant women with congenital heart disease. Obstet Gynecol. 2015;126(2):346-54.

8. Kloster S, Tolstrup JS, Olsen MS, Johnsen SP, Sondergaard L, Nielsen DG, et al. Neonatal risk in children of women with congenital heart disease: a cohort study with focus on socioeconomic status. J Am Heart Assoc. 2019;8(21):e013491.

9. Kloster S, Andersen AN, Johnsen SP, Nielsen DG, Ersboll AK, Tolstrup JS. Advanced maternal age and risk of adverse perinatal outcome among women with congenital heart disease: a nationwide register-based cohort study. Paediatr Perinat Epidemiol. 2020;34(6):637-44.

10. Roos-Hesselink J, Baris L, Johnson M, De Backer J, Otto C, Marelli A, et al. Pregnancy outcomes in women with cardiovascular disease: evolving trends over 10 years in the ESC registry of pregnancy and cardiac disease (ROPAC). Eur Heart J. 2019;40(47):3848-55.

11. Ramage K, Grabowska K, Silversides C, Quan H, Metcalfe A. Association of Adult Congenital Heart Disease with pregnancy, maternal, and neonatal outcomes. JAMA Netw Open. 2019;2(5):e193667.

12. Schlichting LE, Insaf TZ, Zaidi AN, Lui GK, Van Zutphen AR. Maternal comorbidities and complications of delivery in pregnant women with congenital heart disease. J Am Coll Cardiol. 2019;73(17):2181-91. 
13. Sidlik R, Sheiner E, Levy A, Wiznitzer A. Effect of maternal congenital heart defects on labor and delivery outcome: a population-based study. J Matern Fetal Neonatal Med. 2007;20(3):211-6.

14. Hayward RM, Foster E, Tseng ZH. Maternal and fetal outcomes of admission for delivery in women with congenital heart disease. JAMA Cardiol. 2017;2(6):664-71.

15. Warrick CM, Hart JE, Lynch AM, Hawkins JA, Bucklin BA. Prevalence and descriptive analysis of congenital heart disease in parturients: obstetric, neonatal, and anesthetic outcomes. J Clin Anesth. 2015:27(6):492-8.

16. Collins RT 2nd, Chang D, Sandlin A, Goudie A, Robbins JM. National in-hospital outcomes of pregnancy in women with single ventricle congenital heart disease. Am J Cardiol. 2017;119(7):1106-10.

17. Owens A, Yang J, Nie L, Lima F, Avila C, Stergiopoulos K. Neonatal and maternal outcomes in pregnant women with cardiac disease. J Am Heart Assoc. 2018;7(21):e009395.

18. Josefsson A, Kernell K, Nielsen NE, Bladh M, Sydsjo G. Reproductive patterns and pregnancy outcomes in women with congenital heart disease--a Swedish population-based study. Acta Obstet Gynecol Scand. 2011;90(6):659-65.

19. Weiss M, Ryan P, Lokken L, Nelson M. Length of stay after vaginal birth: sociodemographic and readiness-for-discharge factors. Birth. 2004;31(2):93-101.

20. Federspiel JJ, Suresh SC, Darwin KC, Szymanski LM. Hospitalization duration following uncomplicated cesarean delivery: predictors, facility variation, and outcomes. AJP Rep. 2020;10(2):e187-e97.

21. Knudsen LB, Olsen J. The Danish medical birth registry. Dan Med Bull. 1998:45(3):320-3.

22. Bliddal M, Broe A, Pottegard A, Olsen J, Langhoff-Roos J. The Danish medical birth register. Eur J Epidemiol. 2018;33(1):27-36.

23. Lynge E, Sandegaard JL, Rebolj M. The Danish National Patient Register. Scand J Public Health. 2011:39(7 Suppl):30-3.

24. Schmidt M, Schmidt SA, Sandegaard JL, Ehrenstein V, Pedersen L, Sorensen HT. The Danish National Patient Registry: a review of content, data quality, and research potential. Clin Epidemiol. 2015;7:449-90.

25. Schmidt M, Pedersen L, Sorensen HT. The Danish civil registration system as a tool in epidemiology. Eur J Epidemiol. 2014;29(8):541-9.

26. Pedersen CB. The Danish civil registration system. Scand J Public Health. 2011;39(7 Suppl):22-5.

27. Olsen M, Garne E, Svaerke C, Sondergaard L, Nissen H, Andersen HO, et al. Cancer risk among patients with congenital heart defects: a nationwide follow-up study. Cardiol Young. 2014;24(1):40-6.

28. Howards PP, Schisterman EF, Poole C, Kaufman JS, Weinberg CR. "toward a clearer definition of confounding" revisited with directed acyclic graphs. Am J Epidemiol. 2012;176(6):506-11.

29. Textor J, van der Zander B, Gilthorpe MS, Liskiewicz M, Ellison GT. Robust causal inference using directed acyclic graphs: the R package 'dagitty'. Int J Epidemiol. 2016;45(6):1887-94.

30. Jensen VM, Rasmussen AW. Danish education registers. Scand J Public Health. 2011;39(7 Suppl):91-4.

31. UNESCO Institute for Statistic. International standard classification of education. ISCED 2011: UNESCO Institute for Statistics; 2012. [cited 2019 29th of July]. Available from: http://uis.unesco.org/sites/default/files/docum ents/international-standard-classification-of-education-isced-2011-en. pdf

32. Retinformation. Databeskyttelsesloven - LOV nr 502 af 23/05/2018 (the Data Protection Act - LAW no 502 from 23/05/2018, in Danish) 2021 [Available from: https://www.retsinformation.dk/eli/lta/2018/502 (Accessed 3 Aug 2021).

33. Thygesen LC, Daasnes C, Thaulow I, Brønnum-Hansen H. Introduction to Danish (nationwide) registers on health and social issues: structure, access, legislation, and archiving. Scand J Public Health. 2011;39(7 Suppl):12-6.

34. Drenthen W, Pieper PG, Roos-Hesselink JW, van Lottum WA, Voors AA, Mulder BJ, et al. Outcome of pregnancy in women with congenital heart disease: a literature review. J Am Coll Cardiol. 2007;49(24):2303-11.

35. Silversides CK, Grewal J, Mason J, Sermer M, Kiess M, Rychel V, et al. Pregnancy outcomes in women with heart disease: the CARPREG II study. J Am Coll Cardiol. 2018;71(21):2419-30.

36. Lima F, Nie L, Yang J, Owens A, Dianati-Maleki N, Avila C, et al. Postpartum cardiovascular outcomes among women with heart disease from a Nationwide study. Am J Cardiol. 2019;123(12):2006-14.
37. Benahmed N, San Miguel L, Devos C, Fairon N, Christiaens W. Vaginal delivery: how does early hospital discharge affect mother and child outcomes? A systematic literature review. BMC Pregnancy Childbirth. 2017;17(1):289.

38. Brown S, Small R, Faber B, Krastev A, Davis P. Early postnatal discharge from hospital for healthy mothers and term infants. Cochrane Database Syst Rev. 2002;(3):CD002958. https://doi.org/10.1002/14651858.CD002 958.

39. Khan A, Ramsey K, Ballard C, Armstrong E, Burchill LJ, Menashe V, et al. Limited accuracy of administrative data for the identification and classification of adult congenital heart disease. J Am Heart Assoc. 2018;7(2):e007378. https://doi.org/10.1161/JAHA.117.007378.

40. Jepsen B, Jepsen P, Johnsen SP, Espersen GT, Sørensen HT. Validity of diagnoses of cardiac malformations in a Danish population-based hospitaldischarge registry. Int J Risk Saf Med. 2006;18(2):77-81.

41. Agergaard P, Hebert A, Bjerre J, Sorensen KM, Olesen C, Ostergaard JR. Children diagnosed with congenital cardiac malformations at the national university departments of pediatric cardiology: positive predictive values of data in the Danish National Patient Registry. Clin Epidemiol. 2011;3:61-6.

42. Statistic Denmark. Datafortrolighedspolitik (Data confidence policy, in Danish) 2020 [Available from: https://www.dst.dk/Site/Dst/SingleFiles/ GetArchiveFile.aspx?fi=formid\&fo=datafortrolighed\%2D\%2Dpdf\&ext= $\{2\}$ (Accessed 3 Aug 2021).

\section{Publisher's Note}

Springer Nature remains neutral with regard to jurisdictional claims in published maps and institutional affiliations.

Ready to submit your research? Choose BMC and benefit from

- fast, convenient online submission

- thorough peer review by experienced researchers in your field

- rapid publication on acceptance

- support for research data, including large and complex data types

- gold Open Access which fosters wider collaboration and increased citations

- maximum visibility for your research: over $100 \mathrm{M}$ website views per year

At BMC, research is always in progress.

Learn more biomedcentral.com/submissions 